Revista de

Contabilidade e

Organizações
DOI: http://dx.doi.org/10.11606/rco.v10i28.111758
Journal of

Accounting and

Organizations

www.rco.usp.br

\title{
Diversificação das receitas e risco de insolvência dos bancos brasileiros
}

\author{
Carlos André Marinho Vieira ${ }^{\mathrm{a}}$; Luiz Felipe de Araújo Pontes Girão ${ }^{\mathrm{a}}$
}

${ }^{a}$ Universidade Federal da Paraiba

\section{Informações do Artigo}

Histórico do Artigo

Recebido: 03 de março de 2016

Aceito: 27 de outubro de 2016

Palavras-chave:

Diversificação.

Risco de insolvência.

Z-score.

Índice Herfindahl Hirschman.

Instituições Financeiras.

\begin{abstract}
Resumo
Este estudo teve por objetivo investigar a relação entre a diversificação das receitas dos bancos brasileiros e sua relação com o risco de insolvência, testando a hipótese de que uma maior diversificação das receitas pode diminuir o risco de insolvência. A amostra foi composta por instituições financeiras que continham dados relativos ao período de 1997 a 2015. Utilizando-se de modelos de dados em painel e do estimador systemGMM, os resultados indicam que no período estudado a diversificação das receitas das instituições financeiras não influenciou o risco de insolvência dos bancos. Porém, ao analisar o efeito da diversificação entre os bancos abertos e fechados, encontramos evidências de que quando os bancos abertos diversificam suas operações, conseguem diminuir seu risco de insolvência, diferentemente dos bancos fechados. Evidências indicam que a lucratividade aumenta o risco de insolvência dos bancos, enquanto a capitalização está negativamente relacionada ao risco.
\end{abstract}

Copyright (C) 2016 FEA-RP/USP. Todos os direitos reservados

\section{INTRODUÇÃO}

Entre as funções dos bancos, destaca-se a intermediação de recursos entre os agentes superavitários e deficitários de uma economia, sendo estes recursos usados principalmente para financiar investimentos e estimular o consumo. Tais fatos colaboram para a geração de emprego e renda, tornando sua atividade relevante para o crescimento econômico de um país, por este motivo as instituições financeiras são alvo de forte regulamentação, buscando maior eficiência e redução da probabilidade de falência destas instituições.

Uma das formas de se melhorar a eficiência do setor bancário é por meio da diversificação das suas atividades, uma vez que os bancos podem oferecer diversos serviços a seus clientes utilizando apenas uma estrutura administrativa. Diversas teorias podem ser aplicadas a respeito da razão pela qual os bancos diversificam suas operações. Montgomery (1994) cita três abordagens a respeito do porquê de as empresas diversificarem suas operações, sendo estas a visão do poder de mercado, a visão da agência e a visão dos recursos, estando ligadas, respectivamente, à utilização de lucros de outros mercados e sua aplicação em novos segmentos, no interesse dos administradores por trás da diversificação das operações e de uma alocação mais eficiente dos recursos controlados pelas empresas.

Sanya e Wolfe (2011) listam algumas das principais motivações para a diversificação nos bancos, dentre elas a proteção contra o risco de insolvência, que diminui a ocorrência de graves dificuldades financeiras. A diversificação também pode ser usada como um mecanismo para se aumentar a lucratividade e eficiência operacional de uma instituição, principalmente se a escala e escopo de suas operações aumentarem. Também pode ser citada a utilização de receitas diferentes das tradicionais rendas de operações de crédito na diminuição das variações cíclicas na lucratividade, servindo como hedge para estas variações e tornando o lucro contábil mais persistente, onde também se criam pressões competitivas entre os bancos pela maior variedade de segmentos, aumentando a inovação e a eficiência nos serviços oferecidos (SANYA; WOLFE, 2011). Considerando as operações de crédito como atividades tradicionais, os bancos brasileiros diversificam suas atividades pela prestação de serviços bancários, operações de câmbio e arrendamento mercantil, rendas obtidas por meio de aplicações financeiras e

Autor Correspondente: Tel (83) 32167459

E-mail: c.andre.mv@gmail.com (C. A. M. Vieira); lfapg@hotmail.com (L. F. A. P. Girão)

Universidade Federal da Paraíba, Centro de Ciências Sociais Aplicadas - Campus I, Departamento de Finanças e Contabilidade. - Jardim Cidade Universitária CEP 58059900 - Joao Pessoa, PB - Brasil. 
participações societárias.

Todavia, os estudos sobre a diversificação das receitas bancárias não têm sido conclusivos em relação aos seus impactos sobre as instituições financeiras, uma vez que foram encontrados resultados diferentes nos estudos com dados de países emergentes (SANYA; WOLFE, 2011) e desenvolvidos (LEPETIT; NYS; ROUS; TARAZI, 2008); entre bancos grandes e pequenos (STIROH, 2004a; STIROH, 2004b); e entre as várias medidas de diversificação utilizadas na literatura (ELSAS; HACKETHAL; HOLZHÄUER, 2010).

Várias linhas de pesquisa têm sido exploradas com respeito aos reflexos da diversificação para as instituições financeiras, como a sua relação com o valor da empresa (ELSAS; HACKETHAL; HOLZHÄUER, 2010; BAELE; De JONGUE; VERNETT, 2007), lucratividade (TRUJILLO-PONCE, 2013) e risco (STIROH, 2004a; STIROH, 2004b; STIROH, 2006; LEPETIT; NYS; ROUS; TARAZI, 2008; SANYA; WOLFE, 2011). No Brasil, especificamente, esse é um tema relevante, pois observa-se um mercado bancário muito concentrado e com poucos bancos detendo a maior parte dos ativos do sistema. Desta concentração do setor surge a necessidade de se estudar os efeitos da diversificação das receitas de modo a planejar políticas que evitem uma crise generalizada no setor.

Todavia, a preocupação quanto a isso não é recente no país, pois as tentativas do governo brasileiro de regulamentar e aumentar a eficiência do setor bancário foram muitas ao longo do tempo. Dentre as reformas legais mais relevantes, podem ser citadas a Lei no 4.595 de 1964, conhecida como Lei da Reforma Bancária, que reestruturou o Sistema Financeiro Nacional (SFN), a Resolução do Conselho Monetário Nacional $(\mathrm{CMN}) \mathrm{n}^{\circ}$ 1.524 de 21/09/1988, que criou a figura dos bancos múltiplos e incentivou a fusão de outros tipos de instituições financeiras em bancos múltiplos, e os programas de ajuste do sistema financeiro (PROER, PROES). A promulgação da Resolução CMN n ${ }^{0} 1.524$ permitiu aos bancos a exploração de mais de uma atividade, criando economias de escala para a atuação em diversos mercados a partir de uma só estrutura administrativa.

Com base nisso, este trabalho busca contribuir com a literatura empírica que trata sobre os custos e benefícios da diversificação das atividades bancárias, uma vez que os estudos nacionais sobre o tema são limitados. Especificamente, este trabalho tem por objetivo identificar o impacto da diversificação nas operações das instituições financeiras brasileiras sobre o risco de insolvência medido pelo Z-Score. De forma geral, os resultados do trabalho indicam que a diversificação das receitas das instituições financeiras, estudadas sob a forma de concentração destas, não afeta o risco de insolvência daquelas instituições, no período analisado, contrariando resultados anteriores (como Sanya e Wolfe, 2011). O trabalho apresenta evidências semelhantes quando a diversificação é considerada do ponto de vista da quantidade de setores nos quais a empresa opera. Contudo, Sanya e Wolfe (2011) utilizaram apenas bancos listados em bolsas de valores de vários países emergentes, enquanto que a amostra deste artigo contém bancos abertos e fechados.

Ao considerar o impacto da diversificação, levando em conta se o banco têm seus títulos e valores mobiliários negociados no mercado de capitais, os resultados apontaram para a redução do risco de insolvência, semelhante a Sanya e Wolfe (2011), possivelmente por causa do efeito monitoramento sob o qual os bancos abertos estão submetidos (LAEVEN; LEVINE, 2009, HAAN; VLAHU, 2016). Esta pesquisa está organizada da seguinte forma: a) referencial teórico tido como base para a formulação do problema de pesquisa seguido de alguns estudos anteriores sobre o tema discutido; b) metodologia utilizada na análise dos dados; c) análise dos resultados obtidos; e d) considerações finais sobre os resultados obtidos.

\section{REFERENCIAL TEÓRICO}

\subsection{Diversificação nas Instituições Financeiras}

Em 1988, por meio da Resolução do $\mathrm{CMN} \mathrm{n}^{0} 1.524$, o sistema financeiro brasileiro foi desregulamentado e aberto à criação de bancos múltiplos, permitindo que uma mesma instituição pudesse operar em diversos segmentos com uma única estrutura. Com a criação do Plano Real em 1994, as receitas inflacionárias oriundas do floating foram eliminadas, levando as instituições financeiras a compensar essa diminuição de receitas pelo aumento da oferta de crédito, atrativa em razão das altas taxas de juros praticadas no país na época. Estas operações foram motivadas também pelo aumento do crescimento econômico do país, que demandava capital para investimento pelas empresas (CAMARGO, 2009). 
Porém, com o crescimento destas operações, em 2004 este movimento foi freado pela imposição de restrições por parte do governo ao aumento destas operações, podendo ser citadas as exigências de reservas sobre os depósitos à vista e a prazo e a instituição de depósito compulsório sobre os empréstimos concedidos pelas instituições. Ainda conforme Camargo (2009, p. 93) "a substituição dos lucros provenientes das altas taxas por receitas provenientes de serviços levou a uma valorização da figura do cliente [...] baseados nesse modelo, os bancos criam produtos e pacotes de serviços diferenciados". Tais fatos contribuíram para a busca da maximização dos resultados das instituições financeiras por meio do aproveitamento de sua estrutura física para oferecer diversos outros serviços aos seus clientes.

De acordo com Stiroh (2004a) a mudança na estrutura das receitas bancárias, onde começa a surgir com mais força a figura das receitas não relacionadas às operações de crédito (receitas com juros), tem contribuído para o aumento da receita total destas instituições, havendo um senso comum de que esta mudança na estrutura das receitas pode diminuir a volatilidade do lucro e da receita total, reduzindo o risco em razão destas novas formas de obtenção de receita apresentarem-se menos dependentes das condições globais da economia.

Elsas, Hackethal e Holzhäuer (2010, p. 1274) citam que os bancos, ao contrário da maioria dos outros setores, mantêm relações de longo prazo com seus clientes, onde acumulam informações destes que podem ser utilizadas no oferecimento de outros tipos de serviços, gerando economias de escala pelo fato de manter uma única estrutura para oferecer diversos tipos de serviços. Porém, o aproveitamento de uma estrutura já fixada não é o único motivo para a diversificação dos segmentos no qual uma empresa opera. As principais teorias a respeito da razão por trás da diversificação das operações das empresas são citadas por Montgomery (1994), destacando-se: (a) a visão do poder de mercado; (b) a visão da agência; e (c) a visão dos recursos. Na visão do poder de mercado, os benefícios da diversificação ocorrem pela utilização de lucros advindos de um mercado como subsídio para a prática de preços agressivos em outros mercados e pela compra e venda de recursos entre as instituições do conglomerado por preços mais competitivos.

De acordo com a visão da agência, nas empresas onde há a separação entre propriedade e controle, os administradores podem se utilizar de estratégias de diversificação para alcançar seu próprio bem-estar, levando-se em consideração que os acionistas da empresa têm formas de diversificar seus investimentos em várias empresas, diminuindo o seu risco nos investimentos, ao contrário dos administradores, que se utilizam da diversificação de mercados para diminuir o risco da empresa na qual trabalham. Sendo assim, a equipe de gestão poderia diversificar as operações do banco com o objetivo de adquirir experiência no setor e, consequentemente, crescimento profissional, sem necessariamente aumentar o retorno esperado pelos acionistas em razão de uma maior assunção de riscos.

Por fim, a visão da alocação de recursos, ou visão dos recursos afirma, que ao diversificar suas atividades, a empresa pode se utilizar de recursos ociosos originários de outras atividades, fazendo um melhor uso de seus ativos para gerar o retorno pretendido pelos acionistas (MONTGOMERY, 1994). Baele, De Jongue e Vernett (2007) citam outras dimensões nas quais a diversificação pode ser benéfica para as instituições financeiras: (a) a combinação de várias instituições numa só, em forma de conglomerado aumenta a capacidade de geração de receitas ao mesmo tempo que diminui os custos operacionais destas instituições pela economia de escala resultante da divisão do trabalho, tecnologia e informação sobre os vários consumidores dos diferentes produtos bancários; e (b) a informação possuída pelos bancos sobre as relações entre este e seus clientes pode melhorar a administração do risco e dos serviços oferecidos.

\subsection{Evidências Empíricas}

Stiroh (2004a) considerou o aumento da confiança da indústria bancária em atividades não tradicionais para o estudo dos potenciais benefícios da diversificação de suas receitas, principalmente em relação à volatilidade dos lucros e risco de insolvência. Durante o período analisado (de 1984 a 2001), foram encontradas evidências de que a diversificação pode ser benéfica para as instituições na forma de lucros e receitas mais estáveis.

Em relação às receitas específicas, encargos e taxas referentes à prestação de serviços estão altamente correlacionadas com as receitas líquidas de operações de crédito. Há uma associação negativa entre as receitas bancárias decorrentes de atividades não relacionadas com operações de crédito e lucros por unidade de risco. A pesquisa ainda evidenciou que as atividades de intermediação financeira são os maiores entraves para a lucratividade por unidade de risco, sugerindo que a expansão continuada pode resultar em baixos retornos ajustados ao risco. Receitas decorrentes principalmente de administração de investimentos estão altamente associadas à lucratividade por unidade de risco e maior estabilidade do crescimento dos lucros. 
Stiroh (2004b) investigou a relação entre a diversificação das receitas bancárias e a performance ajustada ao risco. Foram usados dados do período de 1984 a 2000 de pequenos bancos comunitários (aqueles cujos ativos totais têm valor menor que US\$ 300 milhões e que não têm ligação com outro banco, tais como holdings). Os resultados mostram que as receitas de atividades diferentes daquelas das de crédito estão relacionadas com uma diminuição da performance ajustada ao risco, podendo esta relação estar ligada ao fato de que os bancos comunitários estão expandindo suas atividades sem a experiência e know-how adequados para dominarem os novos mercados. Os resultados também mostram que empréstimos dos tipos comercial e industrial e receitas de intermediação financeira estão associados ao declínio nos lucros e ao alto risco dos bancos comunitários.

Stiroh (2006) analisou o risco das holdings bancárias (mensurado pela volatilidade das ações dos bancos abertos americanos) no período de 1997 a 2004. Como apresentado em trabalhos anteriores (STIROH, 2004A; STIROH, 2004b), a concentração das receitas foi medida por conjuntos de duas ou cinco variáveis, contidas neste primeiro conjunto o Índice Herfindahl Hirschman ( $\mathrm{IHH})$ entre as receitas de operações de crédito e aquelas diferentes das de operações de crédito e também pela razão entre estas receitas e as receitas operacionais líquidas de suas respectivas despesas. Os resultados sugerem que empréstimos comerciais e industriais, além de atividades diferentes das de crédito, estão relacionadas com altos riscos inerentes às instituições no período estudado.

Na mesma linha de pesquisa, Mercieca, Schaeck e Wolfe (2007) analisaram relatórios anuais de pequenos bancos europeus (considerados aqueles os quais possuíam ativos menores que 450 milhões de euros e sem filiação com holdings bancárias) no período de 1997 a 2003, resultando numa amostra de 755 instituições para o período analisado. O objetivo deste estudo foi analisar se a mudança de atividades ligadas a operações de crédito para outras atividades diferentes destas aumentavam a performance destas instituições. A análise dos resultados evidenciou uma correlação negativa entre as atividades diferentes daquelas de operações de crédito e a performance ajustada ao risco. Estes achados sugerem que os pequenos bancos europeus não estão colhendo os benefícios da diversificação por possivelmente entrarem em mercados nos quais não tem know-how e experiência. No campo das variáveis de controle, o tamanho esteve positivamente relacionado à lucratividade, sendo indício de economias de escala nestas instituições.

Lepetit et al. (2008) investigaram a relação entre o risco dos bancos e a diversificação das suas receitas na indústria de bancos europeia no período de 1996 a 2002 em 14 países europeus, utilizando uma amostra de 734 bancos, sendo 156 destes listados em bolsa. Para mensurar a diversificação das receitas, os autores utilizaram a razão entre as receitas das atividades diferentes das de crédito líquidas de suas respectivas despesas, divididas pelas receitas operacionais líquidas de suas respectivas despesas (esta pode ser entendida como as receitas de operações de crédito líquidas das despesas de captação somadas às receitas não relacionadas às de crédito líquidas das suas despesas correspondentes). Os resultados evidenciaram que os bancos diversificados em segmentos diferentes do de crédito apresentam maior nível de risco que aqueles que se concentram nas atividades de crédito. Também foi apresentada uma relação positiva entre o risco e a diversificação das receitas, sendo esta mais robusta para os pequenos bancos (aqueles em que os ativos totais são menores que 1 bilhão de euros) com o risco positivamente relacionado principalmente à participação das receitas oriundas de taxas cobradas por serviços prestados em relação às receitas totais. Estes resultados são diferentes quando comparados com a relação do risco com as receitas de intermediação financeira, podendo estas implicar numa diminuição do risco para os pequenos bancos.

Sanya e Wolfe (2011) investigaram a diversificação das receitas bancárias em relação à performance e risco destas instituições. A amostra foi formada por 226 bancos listados em 11 diferentes países emergentes, no período de 2000 a 2007. Para se inferir sobre os reflexos da diversificação sobre o risco de insolvência, tal risco foi mensurado pelo Z-score, pelo risco ajustado pelo ROE (Return on Equity) e pelo risco ajustado pelo ROA (Return on Assets). Dentre os resultados obtidos, destaca-se que a diversificação entre e dentro das linhas de negócio aumenta o risco ajustado à lucratividade e diminui o risco de insolvência mensurado pelo Z-score.

Também destaca-se o fato de que não há ligação entre alta participação de receitas das atividades diferentes das de crédito e lucratividade, além de que as receitas com taxas pela prestação de serviços aumentam a lucratividade e diminuem o risco destas instituições. Por fim, a criação de valor como resultado da diversificação das receitas bancárias em países emergentes é mostrada como outro resultado relevante da pesquisa.

\section{METODOLOGIA}

\subsection{Seleção e composição da amostra}


Na composição da amostra, foram utilizados dados de todas as instituições financeiras atuantes no Brasil e classificadas como bancos que apresentavam balancetes semestrais individuais no site do Banco Central do Brasil (www.bcb.gov.br), onde foram coletados dados referentes ao período de 1994 a 2015. A escolha de tal período é justificada pelo fato deste coincidir com a implantação do Plano Real, o qual contribuiu para o Brasil ter seus índices inflacionários estabilizados após anos de hiperinflação.

Dos bancos inicialmente utilizados na amostra foram coletados dados a respeito da estrutura de suas receitas, o valor do ativo total, patrimônio líquido e empréstimos efetuados ao final do semestre, além do lucro operacional de cada período. Pela falta de alguns dos dados referentes às variáveis utilizadas no modelo, foram feitas exclusões de algumas destas instituições. Além disso, foram excluídos os bancos que apresentaram patrimônio líquido negativo em qualquer um dos períodos da amostra. Por fim, com o intuito de montar um painel balanceado, foram excluídos da amostra os bancos que deixaram de apresentar informações para algum dos períodos. Como algumas medidas de risco demandavam médias que englobavam dados defasados em três anos (seis semestres), não puderam ser computadas as medidas de risco para os anos de 1994, 1995 e 1996, iniciando-se a análise dos dados, efetivamente, a partir do primeiro semestre de 1997 e estendendo-se até o primeiro semestre de 2015.

A amostra final para o modelo que busca inferir o efeito da diversificação sobre o risco é composta por um painel balanceado com 88 instituições, totalizando 3.256 observações para 37 semestres. A coleta de dados sobre o tipo de banco (aberto ou fechado) foi realizada no sítio da Comissão de Valores Mobiliários na internet (www. cvm.gov.br). As variáveis macroeconômicas representativas do Produto Interno Bruto (PIB) e inflação (IPCA) foram coletadas nos endereços eletrônicos do Instituto Brasileiro de Geografia e Estatística (www.ibge.gov.br) e Banco Central do Brasil.

\subsection{Desenvolvimento de Hipóteses e Definição dos Modelos empregados}

Considerando que existam efeitos da diversificação das receitas na diminuição do risco de insolvência das instituições financeiras e que existe ainda uma associação negativa entre o grau de diversificação e o risco destas instituições (e.g. SANYA; WOLFE, 2011), apresenta-se a seguinte hipótese de pesquisa:

$\mathrm{H}_{1}$ : A diversificação das receitas influencia positivamente na redução do risco de insolvência das instituições financeiras.

No modelo utilizado para se testar a hipótese de pesquisa, o Z-score é utilizado para se medir a probabilidade de insolvência de uma instituição financeira i no ano t, sendo que quanto maior o seu valor, menor a probabilidade (e consequentemente, o risco) de insolvência inerente à cada instituição. O Z-score utilizado nesta pesquisa é calculado pela abordagem de Boyd, De Nicoló e Jalal (2006, seção III.A) modificada por Lepetit e Strobel (2013) e pela abordagem de Yeyati e Micco (2007). O cálculo do Z-Score consiste basicamente no somatório do ROA, conforme equação (1), com a razão do patrimônio líquido pelo ativo total, divididos pelo desvio padrão do ROA, como consta na equação (2):

$$
\begin{gathered}
R O A_{i, t}=\frac{\text { Lucro Operacional }_{i, t}}{\text { Ativo Total (final) } i, t} \\
Z-\text { score }_{i, t}=\frac{\operatorname{ROA}_{i, t}+\frac{\mathrm{PL}_{i, t}}{\text { Ativo }_{i, t}}}{\sigma \mathrm{ROA}_{i, t}}
\end{gathered}
$$

Na abordagem de Boyd et al. (2006) modificada por Lepetit e Strobel (2013), são utilizados a média móvel do ROA e da razão entre Patrimônio Líquido e Ativo Total, além do desvio padrão móvel do ROA para os últimos 3 anos. Na abordagem de Yeyati e Micco (2007), são utilizadas a média e desvio padrão móveis do ROA para os últimos 3 períodos, enquanto que a razão entre o Patrimônio Líquido e o Ativo Total é calculada para o período corrente. Para diferenciar estas variáveis, consideraremos a abordagem de Boyd et al. (2006) modificada 
por Lepetit e Strobel (2013) como Z-Score 1 e a abordagem de Yeyati e Micco (2007) como Z-Score 2.

Para se mensurar a diversificação das receitas, foi utilizado o IHH separando as receitas por sua natureza de acordo com o Plano Contábil das Instituições do Sistema Financeiro Nacional (COSIF). De acordo com Paulo, Medeiros e Dantas (2011, p. 13) o IHH para um período t é calculado pelo somatório do quadrado da participação percentual $p$ de cada tipo de receita, sendo seu cálculo mostrado pela equação (3):

$$
I H H_{t}=\sum_{i=1}^{N} p_{i}^{2}
$$

O índice foi manipulado para ajudar na interpretação dos dados, onde diminuiu-se do número 1 (um) o valor do IHH original (1-IHH), o que indica que quanto maior o índice, maior a diversificação das receitas da instituição financeira. Este índice será denominado de IHH ajustado (IHHaj). Outra medida de diversificação utilizada no estudo foi o número de receitas operacionais $(\mathrm{N})$ auferidas no período, o que indica o número de mercados em que a instituição atua. Esta medida foi escolhida por ser uma representação alternativa ao IHH, sendo que este último fornece uma medida de concentração entre as receitas auferidas, onde mesmo correlacionado com o número de mercados nos quais a empresa atua, não indica com total confiabilidade a variabilidade destes segmentos. Também devem ser reconhecidas as limitações da variável N, onde uma receita eventual de pequeno montante pode não caracterizar uma real diversificação dos segmentos nos quais uma instituição atua.

Algumas variáveis de controle foram incluídas para refletir outras características que podem afetar o risco de insolvência das instituições financeiras. Estas variáveis foram divididas entre variáveis específicas do setor e macroeconômicas. Dentre as variáveis específicas do setor, foram consideradas aquelas utilizadas no trabalho de Sanya e Wolfe (2011), dentre as quais o tamanho da instituição, sua alavancagem, lucratividade, índice de operações de crédito e crescimento dos ativos.

O tamanho da instituição foi mensurado pelo logaritmo do seu ativo total, assim como em vários trabalhos anteriores que utilizaram esta medida como variável de controle (STIROH, 2004A; STIROH, 2004B; MERCIECA et al., 2007; LEPETIT et al., 2008; SANYA; WOLFE, 2011) sob a justificativa de que alguns bancos grandes são "grandes demais para falir", pesando o fato de que pela maior escala de suas operações e pelo risco que sua queda geraria para a economia, esta instituição possui uma garantia implícita de ajuda governamental em caso de dificuldades financeiras. Essa garantia implícita pode fazer com que instituições maiores atuem em mercados mais arriscados como forma de se obter maiores retornos.

Por outro lado, pela importância sistêmica da instituição, o governo pode regular esses bancos de modo a limitar o risco assumido pelas suas operações. Essa característica também gera oportunidades maiores de diversificação em função de sua maior estrutura. A vantagem que os grandes bancos apresentam em realizar operações de crédito em proporção maior e de melhor qualidade pode ser citado como outra razão para uma relação positiva entre o tamanho e baixos níveis de risco (SANYA; WOLFE, 2011). Para esta medida, o valor dos ativos foi corrigido pelo índice de inflação para uma mesma data.

Por outro lado, utilizamos uma medida alternativa do tamanho da instituição, representada através de duas variáveis dummies nomeadas Small e Big, que representam os 25\% menores e maiores bancos, respectivamente, em cada ano. Esta medida tem por objetivo captar qualquer relação não linear entre o tamanho das instituições e seu risco de insolvência.

A variável representativa da capitalização, também chamada de alavancagem ou grau de endividamento, também foi utilizada em trabalhos anteriores como variável de controle para o risco de insolvência (STIROH, 2004A; STIROH, 2004B; MERCIECA et al., 2007; LEPETIT et al., 2008; SANYA; WOLFE, 2011) com base no pressuposto de que uma maior capitalização (menor endividamento) reduz a probabilidade de insolvência de uma instituição. Esta variável foi mensurada pela razão entre o Patrimônio Líquido e o Ativo Total da instituição.

Alucratividade foi representada pelo ROA sob o pressuposto de que se um banco com pequena lucratividade decide diversificar, maior risco de insolvência pode ser incorretamente atribuído à decisão de diversificar. Esta mesma variável foi utilizada em trabalhos anteriores sobre diversificação de receitas (Lepetit et al., 2008; Sanya \& Wolfe, 2011).

Para se medir o índice de operações de crédito foi usada a variável Empréstimos totais sobre o valor dos Ativos Totais (STIROH, 2004B; MERCIECA et al., 2007; LEPETIT et al., 2008; SANYA; WOLFE, 2011) pois, em relação ao prazo de recebimento destas operações de crédito, são ativos menos líquidos e por não estarem disponíveis de imediato para a liquidação de alguma dívida, influem no risco de insolvência das instituições 
financeiras.

A última das variáveis setoriais adicionada ao modelo foi o crescimento anual dos ativos (de t-2 para t), levando em consideração que o crescimento desordenado pode fazer com que uma instituição enfrente problemas de liquidez, onde os investimentos em capital fixo ou em capital de giro podem diminuir o fluxo de caixa para o pagamento de dívidas. Utilizamos a taxa de crescimento/redução das atividades real das instituições (acima da inflação). Esta variável foi utilizada em outros trabalhos com o mesmo objetivo (STIROH, 2004A; STIROH, 2004B; MERCIECA et al., 2007; LEPETIT et al., 2008; SANYA; WOLFE, 2011).

Outra característica institucional investigada nos estudos sobre risco é o fato de a instituição negociar seus títulos e valores mobiliários no mercado de capitais. Inserimos uma variável dummy para captar o efeito da negociação de valores mobiliários no mercado de capitais brasileiros no risco de insolvência. A variável Aberto apresenta valor 1 (um) quando um banco negocia títulos e valores mobiliários no mercado de capitais brasileiro e 0 (zero) do contrário. Lepetit et al. (2008) utilizaram uma sub-amostra com bancos listados em bolsa para avaliar o impacto da diversificação no risco de insolvência. Espera-se que bancos abertos assumam um maior risco para suas operações devido a pressão de acionistas. Por outro lado, o acesso mais rápido ao mercado de capitais, uma maior qualidade das informações financeiras divulgadas e melhores práticas de governança corporativa (características esperadas em empresas listadas) podem significar um menor custo de capital e menor risco (HAAN; VLAHU, 2016).

As variáveis macroeconômicas utilizadas no modelo são representativas do risco sistemático ao qual todas as empresas estão sujeitas, podendo estas variáveis influenciar o risco de insolvência e a diversificação do portfólio de aplicações dos bancos. Foram escolhidas com base em trabalhos anteriores o crescimento do PIB, fornecido pelo IBGE e a taxa de inflação (SANYA; WOLFE, 2011) medida pelo IPCA, sob o pressuposto de que as variações na economia podem reduzir ou alavancar algum tipo de operação das instituições financeiras, assim como seu risco.

Adicionalmente, foram inseridas variáveis referentes à competição do mercado, representadas pelo IHH mensurado a partir dos valores dos Ativos de todas as instituiç̃es financeiras operantes num dado período t. O índice indica maior competição para valores mais baixos e menor competição para valores mais altos. A adição destas variáveis resulta na equação (4), a qual será utilizada para se inferir os reflexos da diversificação de receitas sobre o risco de insolvência dos bancos brasileiros no período de 1997 a 2015.

$$
\begin{aligned}
\mathrm{Z}_{-} \text {score }_{i, \mathrm{t}}= & \beta_{0}+\beta_{1} \mathrm{IHHaj}_{\mathrm{i}, \mathrm{t}}+\beta_{2} \mathrm{~N}_{\mathrm{i}, \mathrm{t}}+\beta_{3} \text { Tamanho }_{\mathrm{i}, \mathrm{t}}+\beta_{4} \frac{\mathrm{PL}}{\text { Ativo }_{\mathrm{i}, \mathrm{t}}}+\beta_{5} \mathrm{ROA}_{\mathrm{i}, \mathrm{t}} \\
& +\beta_{6} \frac{\mathrm{Emp}}{\text { Ativo }_{i, \mathrm{t}}}+\beta_{7} \text { Cresc }_{\text {Ativos } \mathrm{i}, \mathrm{t}}+\beta_{8} \text { Aberto }_{\mathrm{i}, \mathrm{t}}+\beta_{9} \mathrm{PIB}_{\mathrm{t}}+\beta_{10} \mathrm{IPCA}_{\mathrm{t}} \\
& +\beta_{11} \text { Concorrência }_{\mathrm{t}}+\varepsilon
\end{aligned}
$$

Uma vez que cada instituição pode conter características não observáveis específicas, utilizamos estimadores de efeitos fixos (Fixed Effects - FE) para investigar a relação entre a diversificação dos bancos e seu risco de insolvência. Além disso, algumas características que afetam o risco dos bancos são difíceis de mensurar ou identificar em uma equação (heterogeneidade não observável). Ao não considerar a influência dessas características, os coeficientes podem tornar-se enviesados pela correlação entre os coeficientes e as variáveis explicativas (SANYA; WOLFE, 2011; TRUJILLO-PONCE, 2013). Para dirimir esse problema, fizemos uso do método dos momentos generalizados (Generalized Method of Moments - GMM), estimador desenvolvido por Arellano e Bover (1995) e Blundell e Bond (1998), também conhecido por system-GMM.

\section{ANÁLISE DOS RESULTADOS}

\subsection{Estatísticas Descritivas}

Na tabela 1 são apresentadas as estatísticas descritivas da amostra. Nossa análise inicia-se pelo estudo 
das variáveis dependentes do modelo, que representam o risco de insolvência dos bancos: Z-Score1 e Z-Score2. $\mathrm{O}$ Z-Score mede o risco de insolvência em relação à probabilidade de que os resultados negativos possam exaurir as reservas de capital do banco, sendo assim, quanto menor o valor do Z-Score maior o risco de insolvência. Os dois indicadores de Z-Score mostram médias próximas a 9,50. Para uma amostra composta por pequenos bancos europeus (MERCIECA; SCHAEK; WOLFE, 2007) e países emergentes (SANYA; WOLFE, 2011), foram encontradas médias de 58,8 e 17,69, respectivamente. Sendo assim, observa-se que os bancos brasileiros que compõem a amostra apresentam maior risco do que os estudados pelos referidos autores.

O IHH ajustado mostra uma média com valor aproximado de 0,549 , próxima ao valor mediano da distribuição, indicando uma tendência central para esta variável. Ao estudar instituições financeiras espanholas, Trujillo-Ponce (2013) encontrou médias para este índice próximas a 0,725, indicando maior segregação entre os ganhos advindos dos diferentes tipos de atividades operacionais, comparando-se com as instituições brasileiras. Porém, ao contrário do referido estudo, que classificou as atividades principais dos bancos em 4 (quatro), nosso trabalho utiliza os critérios do COSIF, que classifica os tipos de receita entre 9 (nove) grupos. O valor mínimo de 0,0000 para esta variável indica um banco que explora apenas uma atividade econômica.

Ao mesmo tempo, observamos que o número de mercados nos quais os bancos operam $(\mathrm{N})$, apresenta média próxima a 6 (seis), assim como sua mediana, indicando um alto número de atividades os quais estes exploram. $\mathrm{Na}$ amostra, as instituições mais diversificadas exploram um total de 8 (oito) atividades produtivas diferentes, que é o limite estabelecido pelo COSIF. O número mínimo para esta variável indica um banco concentrou-se apenas numa atividade para obtenção de receita durante um período. Importante salientar que este valor mínimo corresponde a apenas uma observação contida na amostra.

$\mathrm{Na}$ apresentação das estatísticas sobre o tamanho das instituições, utilizamos os valores originais, uma vez que nos modelos de regressão estes valores foram ajustados para considerar o impacto da inflação no tamanho das instituições. A variabilidade do tamanho das instituições, medida pelo valor dos seus ativos totais, mostra que a nosso banco de dados foi composto tanto por bancos com aplicações em ativos na casa dos trilhões quanto por instituições com pouco mais de R $\$ 13$ milhões em aplicações. Os bancos apresentam ativos com valores médios de $\mathrm{R} \$ 193$ bilhões. Comparando-se esse valor com a mediana, observa-se que a maior parte da amostra se constitui de bancos pequenos e médios.

Como afirmado anteriormente, a natureza de suas operações faz com que os bancos utilizem principalmente do capital de terceiros para obter lucro, sendo que normalmente, a proporção entre o capital próprio e os ativos totais é baixa. Esta afirmação é corroborada pela média e mediana da relação entre Patrimônio Líquido e Ativo Total, onde em média apenas $8,67 \%$ dos ativos totais destas instituições são financiados por capital próprio. As instituições que apresentaram valores negativos para esta variável foram excluídas da amostra. $O$ valor mínimo para esta variável chega a $0,03 \%$, onde é de se imaginar que valores mínimos representem bancos os quais seu Patrimônio Líquido foi, possivelmente, afetado por sucessivos prejuízos. Bancos pouco capitalizados podem acarretar sérios riscos ao sistema financeiro, sendo função do Banco Central do Brasil evitar a excessiva alavancagem destas instituições. Por fim, os valores máximos representam, possivelmente, instituições que não realizam atividades de intermediação de recursos, para a qual são necessários altos montantes de capitais de terceiros.

Uma análise da lucratividade dos bancos objeto da amostra no período estudado indica que em média, as instituições auferiram retornos positivos em relação aos seus ativos, sendo este retorno próximo a 9,41\%, onde destacam-se os valores máximos e mínimos. No primeiro um banco chega a acumular lucros que correspondem a aproximadamente 4 vezes o valor dos seus ativos totais. No outro extremo, uma instituição obteve pequena margem de lucro, de apenas $0,04 \%$ o valor dos seus ativos totais.

As operações de crédito (empréstimos) representam em média 8,67\% dos ativos dos bancos no período estudado, indicando que estas operações estão entre as de menor destaque nestas instituições. Isso mostra-se um afastamento do modelo de bancos como intermediários financeiros. Os pontos extremos de máximo e mínimo mostram instituições nas suas aplicações ativas são representadas em mais da metade por empréstimos, enquanto outras não se utilizam destas operações para a obtenção de receitas.

Ao analisar as características do crescimento dos ativos dos bancos brasileiros no período estudado, observa-se um alto crescimento no mercado financeiro brasileiro, onde a média de crescimento real de um ano para o outro foi de $37,46 \%$. Os valores máximos indicam possivelmente o crescimento dos bancos pela incorporação e fusão de instituições, sendo operações de grande magnitude. Os valores mínimos indicam possivelmente a dissolução de sociedades através da venda de suas operações, cisão em diferentes empresas ou o abandono de algum segmento de mercado. $15,97 \%$ das observações na nossa amostra foram compostas de bancos abertos. 
Tabela1. Estatísticas Descritivas

\begin{tabular}{|c|c|c|c|c|c|}
\hline Variáveis & Média & Mediana & D.P. & Máximo & Mínimo \\
\hline Z-Score1 & 9,4589 & 5,3340 & 12,4358 & 113,8787 & 0,5038 \\
\hline Z-Score2 & 9,4241 & 5,1219 & 12,6688 & 119,3953 & 0,4478 \\
\hline IHHaj & 0,5486 & 0,5865 & 0,1825 & 0,8421 & 0,0000 \\
\hline $\mathrm{N}$ & 6,1809 & 6,0000 & 1,2012 & 8,0000 & 1,0000 \\
\hline Ativos (\$ mi) & $193.294,03$ & $6.251,41$ & $741.211,77$ & $8.752 .261,20$ & 13,12 \\
\hline PL/Ativos & 0,0891 & 0,0382 & 0,1428 & 0,9527 & 0,0003 \\
\hline ROA & 0,0941 & 0,0656 & 0,1387 & 4,3205 & 0,0004 \\
\hline Emp/Ativos & 0,0867 & 0,0611 & 0,0891 & 0,6637 & 0,0000 \\
\hline CrescAtivos & 0,3746 & 0,0667 & 3,5529 & 162,3632 & $-0,9968$ \\
\hline Aberto & 0,1597 & 0,0000 & 0,3664 & 1,0000 & 0,0000 \\
\hline PIB & 0,0183 & 0,0217 & 0,0414 & 0,1182 & $-0,0587$ \\
\hline IPCA & 0,0317 & 0,0294 & 0,0167 & 0,0931 & $-0,0062$ \\
\hline IHHAtivos & 0,1098 & 0,1005 & 0,0498 & 0,1982 & 0,0496 \\
\hline
\end{tabular}

Fonte: Elaboração Própria

Considerando o índice de concentração das instituições, Trujillo-Ponce (2013) estabelece que valores para o IHH acima de 0,18 indicam mercados altamente concentrados enquanto que valores abaixo de 0,10 indicam mercados mais competitivos. Na nossa amostra cobre períodos de alta e baixa concentração de bancos operantes no país. A média deste indicador aproxima-se à de mercados com equilíbrio competitivo.

\subsection{Relação Entre Diversificação das Receitas e o Risco dos Bancos}

Os resultados obtidos pelas estimações são apresentados na tabela 2. Comparamos os resultados obtidos pelos estimadores de FE com os estimadores de system-GMM. Observa-se que há algumas diferenças entre os resultados dos dois estimadores, que podem ser justificadas pela possível endogeneidade mitigada pelo systemGMM, o que torna este último um estimador mais confiável. Através da estatística F (estimadores FE) e do teste de Wald para significância conjunta dos regressores (estimadores system-GMM), a um nível de significância de 1\% rejeitamos a hipótese nula de que algum dos modelos de regressão foi especificado incorretamente.

Observa-se que a diversificação, medida tanto em relação à concentração de receitas quanto em relação ao número de atividades exploradas pelos bancos em determinado período, não se mostra estatisticamente significante em nenhum dos modelos estudados, indicando que a opção de uma empresa em concentrar-se em um ou vários setores não influencia o seu risco de insolvência.

Dado este resultado, pode-se inferir que a diversificação não traz benefícios em forma de diminuição do risco, mesmo com as vantagens discutidas na literatura onde a diversificação entre vários setores de atuação pode melhorar os resultados destas instituições em cenários de mudanças cíclicas da economia, sendo estes menos dependentes de receitas cíclicas quando o cenário econômico não permitir uma melhor obtenção de lucro através destas. Estes resultados divergem de Stiroh (2004a), Stiroh (2006) e Sanya e Wolfe (2011), que encontraram uma relação positiva entre a diversificação a diminuição do risco das instituições financeiras. Porém, Stiroh (2004b) e Lepetit et al. (2008), encontraram resultados diferentes, onde a diversificação aumenta o risco dos bancos. Mercieca et al. (2007) não encontraram relação estatisticamente significante entre as duas variáveis, resultados semelhantes aos encontrados por esta pesquisa.

De acordo com Baele, De Jongue e Vernett (2007) o risco indiossincrático da instituição tende a diminuir de acordo com o tamanho desta. Ao examinar o coeficiente das regressões para a variável que representa o tamanho dos bancos, observamos uma divergência entre os resultados obtidos pelos estimadores de FE e system-GMM. Considerando estes últimos mais eficientes, concluímos que não há evidências que confirmem a hipótese de que o tamanho da instituição estaria relacionado com a diminuição do seu nível de risco (STIROH, 2006; BAELE; DE JONGUE; VERNETT, 2007; SANYA; WOLFE, 2011).

Em todos os modelos estimados, verifica-se a significância estatística das variáveis representativas 
da capitalização e da lucratividade com o risco de insolvência. O coeficiente positivo da variável capitalização indica que quanto maior a capitalização do banco, menor o risco de insolvência deste. Este resultado é consistente com Lehar (2005) que afirma que o capital próprio protege os bancos de uma quebra quando o valor dos seus ativos diminui, reduzindo assim o risco de insolvência. Porém, o resultado diverge de Baele, De Jongue e Vernett (2007), que encontrou uma correlação negativa entre o nível de risco e a capitalização bancária, onde Carlson (2004) argumenta que pelo fato do capital próprio ter um custo maior que o capital de terceiros, um alto nível de capitalização pode diminuir o desempenho de um banco se os proprietários decidirem proteger seu capital através de investimentos conservadores e, por consequência, menos rentáveis.

Ao contrário do que indica a maior parte da literatura empírica, onde uma maior lucratividade está ligada a um menor nível de risco, obtivemos resultados divergentes de Sanya e Wolfe (2011), que encontraram uma relação positiva e significante para esta variável, onde uma maior lucratividade torna os resultados dos bancos mais estáveis e risco de insolvência menor para estas instituições. Estes resultados podem estar ligados ao fato de os bancos utilizarem uma maior parcela de capitais de terceiros para aumentar sua lucratividade. Ao mesmo tempo em que crescem seus resultados, o risco aumenta na mesma proporção.

A variável Empréstimos/Ativos apresentou significância em apenas um modelo analisado. Numa análise mais detalhada da literatura sobre o resultado para a variável Empréstimos/Ativos, alguns autores indicam que este tipo de receita é mais estável, pois os clientes são menos propensos a mudar de instituição quando realizam operações de crédito (DEYOUNG; ROLAND, 2001), porém foi observado apenas um pequeno efeito desta variável no risco de insolvência dos bancos no período analisado.

O coeficiente negativo obtido para a variável representativa do crescimento real dos ativos entre $t-2$ e $t$ indica que um crescimento desenfreado das operações de uma instituição provoca um aumento no risco de insolvência desta. Porém, esta variável não mostrou significância estatística em nenhum dos modelos analisados. A literatura indica que uma estratégia de rápido crescimento das operações proporciona diversificação indiscriminada dos investimentos, sendo que a pressão por crescimento torna os gestores "míopes" aos investimentos executados (SANYA; WOLFE, 2011), porém, esse fenômeno não foi observado nos resultados deste trabalho.

Tabela 2. Efeitos da diversificação no risco de insolvência dos bancos atuantes no Brasil (1997-2015)

\begin{tabular}{|c|c|c|c|c|}
\hline \multirow{2}{*}{$\begin{array}{l}\text { Estimador } \\
\text { Variáveis }\end{array}$} & \multicolumn{2}{|c|}{ Panel Data (Fixed Effects) } & \multicolumn{2}{|c|}{ system-GMM } \\
\hline & Z-Score1 & Z-Score2 & Z-Score1 & Z-Score2 \\
\hline Z-Score $_{\mathrm{t}-1}$ & - & - & $\begin{array}{c}0,8435 * * * \\
(0,0230)\end{array}$ & $\begin{array}{c}0,7145 * * * \\
(0,0578)\end{array}$ \\
\hline $\mathrm{Z}^{-S_{\text {s }}-2}$ & - & - & $\begin{array}{l}-0,0794 \\
(0,0543)\end{array}$ & $\begin{array}{l}-0,0471 \\
(0,1018)\end{array}$ \\
\hline IHHaj & $\begin{array}{l}-4,1396 \\
(2,8155)\end{array}$ & $\begin{array}{l}-2,4029 \\
(2,4181)\end{array}$ & $\begin{array}{c}0,2154 \\
(1,0906)\end{array}$ & $\begin{array}{c}1,2283 \\
(1,9468)\end{array}$ \\
\hline $\mathrm{N}$ & $\begin{array}{l}-0,5312 \\
(0,7769)\end{array}$ & $\begin{array}{l}-0,6568 \\
(0,8864)\end{array}$ & $\begin{array}{l}-0,1014 \\
(0,4435)\end{array}$ & $\begin{array}{l}-0,0693 \\
(0,4807)\end{array}$ \\
\hline LogAtivos & $\begin{array}{l}2,0844^{*} \\
(1,2063)\end{array}$ & $\begin{array}{c}2,8355 * * \\
(1,2153)\end{array}$ & $\begin{array}{c}0,6034 \\
(0,6760)\end{array}$ & $\begin{array}{c}0,9070 \\
(1,4793)\end{array}$ \\
\hline $\mathrm{PL} /$ Ativos & $\begin{array}{c}27,3362 * * * \\
(6,6909)\end{array}$ & $\begin{array}{c}37,7277^{*} * \\
(7,8503)\end{array}$ & $\begin{array}{c}11,9644 * * * \\
(2,1509)\end{array}$ & $\begin{array}{c}29,6480 * * * \\
(5,0295)\end{array}$ \\
\hline $\mathrm{ROA}$ & $\begin{array}{c}-9,3783 * * * \\
(2,2577)\end{array}$ & $\begin{array}{c}-8,8773 * * \\
(2,2192)\end{array}$ & $\begin{array}{c}-3,6825^{* *} \\
(1,5384)\end{array}$ & $\begin{array}{c}-3,7670 * * \\
(1,6349)\end{array}$ \\
\hline Emp/Ativos & $\begin{array}{c}3,8635 \\
(9,4935)\end{array}$ & $\begin{array}{c}4,2030 \\
(7,9859)\end{array}$ & $\begin{array}{l}15,4839 \\
(5,2561)\end{array}$ & $\begin{array}{c}19,6183 * * \\
(9,7267)\end{array}$ \\
\hline CrescAtivos & $\begin{array}{l}-0,0259 \\
(0,0418)\end{array}$ & $\begin{array}{l}-0,0929 \\
(0,0727)\end{array}$ & $\begin{array}{l}-0,0079 \\
(0,0166)\end{array}$ & $\begin{array}{l}-0,0257 \\
(0,0432)\end{array}$ \\
\hline Aberto & $\begin{array}{c}-2,0363^{*} \\
(1,1776)\end{array}$ & $\begin{array}{l}-1,9831 \\
(1,2051)\end{array}$ & $\begin{array}{l}-0,9632 \\
(1,3140)\end{array}$ & $\begin{array}{c}0,1152 \\
(1,6981)\end{array}$ \\
\hline PIB & $\begin{array}{c}10,4975 * * * \\
(3,5251)\end{array}$ & $\begin{array}{r}9,2264 * * \\
(3,6003)\end{array}$ & $\begin{array}{r}3,2203 * * \\
(1,5467)\end{array}$ & $\begin{array}{c}2,1171 \\
(2,0099)\end{array}$ \\
\hline
\end{tabular}


Tabela 2. Efeitos da diversificação no risco de insolvência dos bancos atuantes no Brasil (1997-2015) (continuação)

\begin{tabular}{|c|c|c|c|c|}
\hline \multirow{2}{*}{$\begin{array}{l}\text { Estimador } \\
\text { IPCA }\end{array}$} & \multicolumn{2}{|c|}{ Panel Data (Fixed Effects) } & \multicolumn{2}{|c|}{ system-GMM } \\
\hline & $\begin{array}{l}23,3723 * \\
(12,8263)\end{array}$ & $\begin{array}{l}21,0176^{*} \\
(12,2063)\end{array}$ & $\begin{array}{l}-9,2281 \\
(6,9239)\end{array}$ & $\begin{array}{c}-10,5356 \\
(7,1282)\end{array}$ \\
\hline IHHAtivos & $\begin{array}{c}-29,4516^{* * *} \\
(8,6933)\end{array}$ & $\begin{array}{c}-26,1128 * * * \\
(8,2264)\end{array}$ & $\begin{array}{c}9,7270 \\
(6,5746)\end{array}$ & $\begin{array}{c}10,8918 \\
(10,0763)\end{array}$ \\
\hline Intercepto & $\begin{array}{c}-5,2606 \\
(14,5521)\end{array}$ & $\begin{array}{l}-14,3008 \\
(14,8968)\end{array}$ & $\begin{array}{l}-5,9196 \\
(6,6345)\end{array}$ & $\begin{array}{l}-10,8173 \\
(17,9189)\end{array}$ \\
\hline Teste F / Wald $\chi^{2 \text { (a) }}$ & $6,02 * * *$ & $5,56^{* * *}$ & $2.913,02(13)^{* * *}$ & $1.279,69(13) * * *$ \\
\hline $\mathrm{R}^{2}$ overall & 0,1821 & 0,2029 & - & - \\
\hline Wald intra-grupo ${ }^{(b)}$ & $2,4 \mathrm{e}+05^{* * *}$ & $2,8 \mathrm{e}+05 * * *$ & - & - \\
\hline Wooldridge $^{(c)}$ & $223,886^{* * *}$ & $41,624 * * *$ & - & - \\
\hline Maior VIF (d) & 2,03 & 2,03 & - & - \\
\hline Arellano-Bond (1) ${ }^{(\mathrm{e})}$ & - & - & $-3,6114 * * *$ & $-2,7226^{* * *}$ \\
\hline Arellano-Bond (2) ${ }^{(\mathrm{e})}$ & - & - & 0,6888 & 0,9145 \\
\hline Sargan test ${ }^{(\mathrm{f})}$ & - & - & $77,32(101)$ & $80,92(101)$ \\
\hline $\mathrm{N}^{\mathrm{o}}$ de instrumentos & - & - & 115 & 115 \\
\hline $\mathrm{N}^{\mathrm{o}}$ de grupos & 88 & 88 & 88 & 88 \\
\hline $\mathrm{N}^{\mathrm{o}}$ de observações & 3.256 & 3.256 & 3.080 & 3.080 \\
\hline Modelo & $(1)$ & (2) & (3) & (4) \\
\hline
\end{tabular}

Notas: Coeficientes (Erros-padrão). Significância estatística: 1\%***, 5\%**, 10\%*. (a) Teste F (FE) ou teste de Wald (systemGMM) de significância geral do modelo de regressão. (b) Teste de Wald para heterocedasticidade intragrupos. ${ }^{(c)}$ Teste de Wooldridge para correlação serial de primeira ordem. (d) Maior valor para o teste de multicolinearidade Variance Inflation Factor (VIF). (e) Teste de correlação serial de ordem (n) usando resíduos de primeiras diferenças, sob a hipótese nula de ausência de correlação serial. ${ }^{(t)}$ Teste de Sargan de sobreidentificação de restrições.

Fonte: Elaboração Própria

Analisando-se as variáveis macroeconômicas, percebe-se que o crescimento do PIB influenciou no risco de insolvência das instituições estudadas, onde o crescimento econômico abre oportunidades para a diminuição do risco dos bancos, sendo que o contrário pode trazer graves problemas financeiros que acarretam dificuldades a serem enfrentadas por estas instituições. Tal variável é estatisticamente significante na maioria dos modelos utilizados, com seu coeficiente apresentando sinal positivo. Os resultados para esta variável são divergentes de Sanya e Wolfe (2011), que encontraram que para períodos de crescimento econômico, os bancos se expõem um maior nível de risco.

A concorrência medida pelo IHH apresenta coeficiente negativo para todos os modelos de FE, apontando significância estatística aos níveis de 1\%. Porém, os resultados não são confirmados pelos estimadores systemGMM. Sendo assim, observa-se que a concentração do setor não desempenha um papel importante no risco de insolvência das instituições financeiras brasileiras no período estudado.

Os resultados obtidos ao substituir a variável LogAtivos por variáveis dummies que representam o tamanho das instituições (Small e Big) são semelhantes aos demonstrados na Tabela 2. Sendo assim, não foram encontradas evidências de quaisquer relações (tanto lineares quanto não-lineares) entre o tamanho dos bancos e seu risco de insolvência.

\subsection{Testes de sensibilidade}

A natureza opaca e complexa (MORGAN, 2002; JONES; LEE; YEAGER, 2012) do sistema financeiro "aumenta a assimetria informacional nas empresas que atuam em negócios bancários", nesse sentido, existem algumas evidências contraditórias no que diz respeito ao nível de aceitação de risco dependendo da estrutura de propriedade dos bancos (HAAN; VLAHU, 2016, p.35). 
Para exemplificar essas evidências contraditórias, baseado numa extensa revisão de literatura sobre o tema (HAAN; VLAHU, 2016, p.35), no início das pesquisas sobre estrutura de propriedade dos bancos (muito concentrado, pouco concentrado, aberto ou fechado etc.) o consenso era de que a concentração de capital (efeito monitoramento) era considerada uma boa forma de se controlar o nível de aceitação de risco dos bancos, porém evidências mais recentes mostraram que a concentração não desempenha um papel importante no monitoramento dos riscos assumidos pelos bancos. Ainda assim, no período pré-crise dos subprimes, os bancos com estrutura de propriedade mais concentrada assumiram mais riscos.

Além da questão relacionada à estrutura de propriedade, analisando a assimetria informacional entre os bancos e seus investidores, existem evidências que apontam que alguns tipos específicos de atividades bancárias (HAGGARD; HOWE, 2012) são mais opacas (com maior assimetria informacional) que outras, o que deve aumentar ainda mais a preocupação com o risco do setor bancário. Com base nisso, nesta seção se analisa se os bancos abertos, que têm, teoricamente, uma estrutura de propriedade mais dispersa do que os bancos fechados, apresentam um efeito mais forte da diversificação no seu risco de insolvência.

Os resultados da Tabela 3 apontam que a diversificação das receitas, medida pelo IHH ajustado, reduz o risco dos bancos brasileiros de capital aberto (variável IHHaj * Aberto). Esse resultado ocorre, possivelmente, pela dispersão do capital acionário e efeito monitoramento exercido pelos agentes do mercado de capitais, uma vez que além da regulamentação do Banco Central, os bancos de capital aberto são regulados pela CVM e demais investidores (pessoas físicas no Brasil e no exterior, além de investidores institucionais). Esse resultado corrobora aqueles apresentados, por exemplo, por Laeven e Levine (2009) onde o risco dos bancos, tendo como proxy o Z-Score, é normalmente alto em bancos com estrutura de propriedade mais concentrada.

Tabela 3. Efeitos específicos da diversificação no risco de insolvência dos bancos abertos e fechados (1997-2015)

\begin{tabular}{|c|c|c|c|c|}
\hline \multirow{2}{*}{$\begin{array}{l}\text { Estimador } \\
\text { Variáveis }\end{array}$} & \multicolumn{4}{|c|}{ Arellano-Bover/Blundell-Bond } \\
\hline & Z-Score1 & Z-Score2 & Z-Score1 & Z-Score2 \\
\hline Z-Score $_{\mathrm{t}-1}$ & $\begin{array}{c}0,8408^{* * * *} \\
(0,0223)\end{array}$ & $\begin{array}{c}0,7152 * * * \\
(0,0529)\end{array}$ & $\begin{array}{c}0,8401^{* * * *} \\
(0,0227)\end{array}$ & $\begin{array}{c}0,7125^{* * * *} \\
(0,0548)\end{array}$ \\
\hline $\mathrm{Z}_{\text {-Score }}{ }_{\mathrm{t}-2}$ & $\begin{array}{l}-0,0757 \\
(0,0542)\end{array}$ & $\begin{array}{l}-0,0474 \\
(0,1019)\end{array}$ & $\begin{array}{l}-0,0757 \\
(0,0550)\end{array}$ & $\begin{array}{l}-0,0494 \\
(0,0988)\end{array}$ \\
\hline IHHaj & $\begin{array}{l}-0,5518 \\
(1,1217)\end{array}$ & $\begin{array}{c}0,9421 \\
(2,1016)\end{array}$ & $\begin{array}{l}-0,2419 \\
(1,0391)\end{array}$ & $\begin{array}{c}0,6508 \\
(2,2086)\end{array}$ \\
\hline $\mathrm{N}$ & $\begin{array}{l}-0,0183 \\
(0,4651)\end{array}$ & $\begin{array}{l}-0,1933 \\
(0,5395)\end{array}$ & $\begin{array}{c}0,0725 \\
(0,4563)\end{array}$ & $\begin{array}{l}-0,0740 \\
(0,5004)\end{array}$ \\
\hline IHHaj * Aberto & $\begin{array}{c}11,6748 * * \\
(5,0382)\end{array}$ & $\begin{array}{r}7,1647 * * \\
(3,5972)\end{array}$ & $\begin{array}{c}11,0161^{* *} \\
(4,6475)\end{array}$ & $\begin{array}{l}7,5310^{*} \\
(4,2577)\end{array}$ \\
\hline $\mathrm{N} *$ Aberto & $\begin{array}{l}-0,6911 \\
(3,0267)\end{array}$ & $\begin{array}{c}1,7742 \\
(2,7170)\end{array}$ & $\begin{array}{l}-0,6129 \\
(2,8030)\end{array}$ & $\begin{array}{c}1,8536 \\
(2,6469)\end{array}$ \\
\hline LogAtivos & $\begin{array}{c}0,5688 \\
(0,7536)\end{array}$ & $\begin{array}{c}0,9002 \\
(0,9404)\end{array}$ & - & - \\
\hline Small & - & - & $\begin{array}{c}0,5206 \\
(1,0808)\end{array}$ & $\begin{array}{l}-0,0923 \\
(0,7092)\end{array}$ \\
\hline Big & - & - & $\begin{array}{c}0,1948 \\
(0,4165)\end{array}$ & $\begin{array}{c}0,3013 \\
(0,7215)\end{array}$ \\
\hline PL/Ativos & $\begin{array}{c}12,5557 * * * \\
(2,3013)\end{array}$ & $\begin{array}{c}29,3772 * * * \\
(4,2463)\end{array}$ & $\begin{array}{c}10,6318^{* * *} \\
(2,1577)\end{array}$ & $\begin{array}{c}27,5642 * * * \\
(3,5116)\end{array}$ \\
\hline ROA & $\begin{array}{c}-3,5985^{* *} \\
(1,6158)\end{array}$ & $\begin{array}{c}-3,8095^{* *} \\
(1,6159)\end{array}$ & $\begin{array}{c}-4,0637 * * \\
(1,6719)\end{array}$ & $\begin{array}{c}-3,6144 * * * \\
(1,4482)\end{array}$ \\
\hline Emp/Ativos & $\begin{array}{c}14,8863 * * * \\
(5,1711)\end{array}$ & $\begin{array}{c}18,2503 * * * \\
(9,3628)\end{array}$ & $\begin{array}{c}13,2575^{* * *} \\
(5,0569)\end{array}$ & $\begin{array}{c}16,9532 * * \\
(8,7418)\end{array}$ \\
\hline CrescAtivos & $\begin{array}{l}-0,0089 \\
(0,0160)\end{array}$ & $\begin{array}{l}-0,0274 \\
(0,0462)\end{array}$ & $\begin{array}{l}-0,0051 \\
(0,0140)\end{array}$ & $\begin{array}{l}-0,0161 \\
(0,0347)\end{array}$ \\
\hline
\end{tabular}


Tabela 3. Efeitos específicos da diversificação no risco de insolvência dos bancos abertos e fechados (1997-2015) (continuação)

\begin{tabular}{|c|c|c|c|c|}
\hline \multirow{2}{*}{$\begin{array}{l}\text { Estimador } \\
\text { Aberto }\end{array}$} & \multicolumn{4}{|c|}{ Arellano-Bover/Blundell-Bond } \\
\hline & $\begin{array}{c}-3,2433 \\
(19,0751)\end{array}$ & $\begin{array}{l}-16,2386 \\
(19,4695)\end{array}$ & $\begin{array}{c}-3,1894 \\
(18,3349)\end{array}$ & $\begin{array}{l}-16,8095 \\
(19,0799)\end{array}$ \\
\hline PIB & $\begin{array}{c}3,2844 * * \\
(1,6109)\end{array}$ & $\begin{array}{c}2,1062 \\
(4,3077)\end{array}$ & $\begin{array}{c}3,3547 * * \\
(1,6502)\end{array}$ & $\begin{array}{c}2,0738 \\
(2,1243)\end{array}$ \\
\hline IPCA & $\begin{array}{l}-9,0285 \\
(7,7601)\end{array}$ & $\begin{array}{c}-10,2723 \\
(8,6687)\end{array}$ & $\begin{array}{l}-8,4203 \\
(6,9596)\end{array}$ & $\begin{array}{c}-11,5553 \\
(8,0728)\end{array}$ \\
\hline IHHAtivos & $\begin{array}{c}9,4613 \\
(6,3164)\end{array}$ & $\begin{array}{l}10,5282 \\
(8,9215)\end{array}$ & $\begin{array}{c}8,9600 \\
(7,2730)\end{array}$ & $\begin{array}{l}10,1919 \\
(9,3560)\end{array}$ \\
\hline Intercepto & $\begin{array}{l}-5,7499 \\
(7,1512)\end{array}$ & $\begin{array}{c}-9,7455 \\
(12,6674)\end{array}$ & $\begin{array}{l}-0,5076 \\
(3,8238)\end{array}$ & $\begin{array}{l}-0,9325 \\
(5,0631)\end{array}$ \\
\hline Wald $\chi^{2 \text { (a) }}$ & $3.299,16(15)^{* * *}$ & $1.118,33(15)^{* * *}$ & $2.837,92(16)^{* * *}$ & $1.578,58(16)^{* * *}$ \\
\hline Arellano-Bond (1) ${ }^{(\mathrm{e})}$ & $-3,6056^{* * *}$ & $-2,7165^{* * *}$ & $-3,6034 * * *$ & $-2,7093 * * *$ \\
\hline Arellano-Bond (2) $)^{(\mathrm{e})}$ & 0,7006 & 0,9155 & 0,7019 & 0,9209 \\
\hline Sargan test ${ }^{(\mathrm{f})}$ & $77,34(101)$ & $81,23(101)$ & $78,22(101)$ & $78,95(101)$ \\
\hline $\mathrm{N}^{\mathrm{o}}$ de instrumentos & 117 & 117 & 118 & 118 \\
\hline $\mathrm{N}^{o}$ de grupos & 88 & 88 & 88 & 88 \\
\hline $\mathrm{N}^{\mathrm{o}}$ de observações & 3.080 & 3.080 & 3.080 & 3.080 \\
\hline Modelo & (5) & (6) & (7) & $(8)$ \\
\hline
\end{tabular}

Notas: Coeficientes (Erros-padrão). Significância estatística: 1\%***, 5\%**, 10\%*. (a) Teste F (FE) ou teste de Wald (systemGMM) de significância geral do modelo de regressão. (e) Teste de correlação serial de ordem (n) usando resíduos de primeiras diferenças, sob a hipótese nula de ausência de correlação serial. ${ }^{\left({ }^{f}\right)}$ Teste de Sargan de sobreidentificação de restrições.

Fonte: Elaboração Própria

\section{CONSIDERAÇÕES FINAIS}

A utilização da diversificação como estratégia para diminuição do risco tem sido objeto de diversos estudos. Num cenário de volatilidade econômica, com bruscas variações nas taxas de juros, aumento da inflação e poucas oportunidades de crescimento da economia, as instituições financeiras podem utilizar sua capacidade instalada e seu know-how para oferecer uma gama de produtos diferentes da tradicional intermediação financeira (operações de crédito).

Neste sentido, o objetivo deste trabalho foi analisar se a diversificação dos segmentos no qual operam as instituições financeiras refletiu no seu risco de insolvência. Buscou-se reduzir o viés de seleção amostral no qual os trabalhos anteriores (SANYA; WOLFE, 2011) se depararam por trabalharem apenas com bancos de capital aberto, incluindo no banco de dados tanto bancos abertos quanto fechados. Os resultados evidenciaram, de maneira geral, que a diversificação das receitas medida pelo grau de concentração destas e sob o ponto de vista do número de mercados em que os bancos atuam não afeta o risco das instituições estudadas. Os resultados encontrados divergem dos achados de Stiroh (2004a), Stiroh (2004b), Stiroh (2006), Lepetit et al. (2008) e Sanya e Wolfe (2011), que encontraram uma relação significante para as variáveis representativas da diversificação. Porém, Mercieca et al. (2007) não encontraram relação entre a diversificação e o risco de insolvência, ao analisarem bancos europeus.

Porém, após a realização de testes de sensibilidade, observou-se que, considerando apenas os bancos abertos, a diversificação está relacionada com a diminuição do risco de insolvência destas instituições. Este resultado pode estar ligado à um maior monitoramento nas instituições financeiras de capital aberto, onde a diversificação pode ser exercida de maneira mais eficiente em razão da pressão dos investidores pela diminuição do risco.

Ao analisar as variáveis de controle, os resultados indicam que bancos mais capitalizados podem utilizarse desta maior proporção de capital próprio quando da ocorrência de dificuldades financeiras, o que diminui seu 
risco de insolvência. Ao contrário do exposto pela literatura específica, os resultados para a variável lucratividade sugerem que bancos que obtém um maior retorno apresentam também maiores níveis de risco. Isso pode estar ligado ao fato de que para se obter maior retorno, os bancos se utilizam de mais recursos de terceiros, obtendo o retorno por meio da aplicação eficiente destes recursos, mas, ao mesmo tempo, aumentando o risco ao qual estão expostos. Por fim, o crescimento dos ativos não apresentou ligação com um maior nível de risco registrado pelos bancos. As oportunidades geradas pelo crescimento econômico foram consideradas fatores de impacto no risco de insolvência destas instituições.

Apesar das limitações advindas da utilização das demonstrações financeiras individuais, este trabalho destaca-se por ter se utilizado de um amplo período para a análise dos dados, iniciando-se a coleta dos dados do período de estabilização econômica alcançada pela economia brasileira até o presente momento. Além disso, pela falta de bibliografia nacional a respeito do assunto, este pode ser considerado pioneiro em apresentar evidências do mercado brasileiro sobre a relação entre diversificação e risco de insolvência já tão consolidada na literatura internacional.

A diferença entre os resultados alcançados por este estudo e os trabalhos internacionais pode advir da diferente regulação à qual estão expostos os bancos em cada país, bem como as práticas específicas relacionadas com os hábitos e costumes entre diferentes países que impactam nos produtos e serviços oferecidos pelos bancos e na sua função social.

Ressalta-se que estes resultados não devem ser tomados como definitivos, uma vez que a falta de pesquisas no cenário nacional abre espaço para a ampliação do estudo. Por exemplo, ao analisar as demonstrações dos grupos econômicos ao invés das demonstrações financeiras individuais, os resultados encontrados poderão ser diferentes dos obtidos neste trabalho, sendo esta uma sugestão para futuras pesquisas sobre o tema. Uma hipótese é que os bancos podem obter os benefícios da diversificação pela sua estrutura como grupo econômico e não para cada instituição individualmente.

Para pesquisas futuras sugere-se, ainda, a utilização de outros modelos econométricos, o estudo de outros setores econômicos e a utilização de outras medidas para o risco de insolvência (e.g. SANFINS; MONTE-MOR, 2014) e diversificação das receitas ou até mesmo a utilização de outras variáveis de controle para se melhor avaliar a influência da diversificação no risco de insolvência destas instituições. O estudo do efeito da diversificação sobre o risco, dividindo as empresas de acordo com seu tamanho também surge como opções para futuras pesquisas, visto que a literatura indica que os bancos menores podem encontrar dificuldades quando decidem diversificar, enquanto que este caminho é mais fácil para os bancos maiores.

\section{REFERÊNCIAS}

ARELLANO, M.; BOVER, O. Another look at the instrumental-variable estimation of error-components models. Journal of Econometrics, v. 68, n. 1, p. 29-52, 1995.

BAELE, L.; De JONGUE, O.; VENNET, R. V. Does the stock market value bank diversification? Journal of Banking \& Finance, v. 31, n. 7, p. 1999-2023, 2007.

BANCO CENTRAL DO BRASIL. Circular BACEN (Banco Central do Brasil) no 1.273 de 29 de Dezembro de 1987. Institui para adoção obrigatória a partir do Balanço de 30.06.88, o anexo PLANO CONTÁBIL DAS INSTITUIÇÕES DO SISTEMA FINANCEIRO NACIONAL - COSIF. Diário Oficial [da] República Federativa do Brasil, Brasília, DF, 29 dez. 1987.

Resolução CMN (Conselho Monetário Nacional) no 1.524 de 21 de Setembro de 1988. Faculta aos bancos comerciais, bancos de investimento, bancos de desenvolvimento, sociedades de crédito, financiamento e investimento a organização opcional em uma única instituição, com personalidade jurídica própria, através de processos de fusão, incorporação, cisão, transformação ou constituição direta, com autorização prévia do Banco Central. Diário Oficial [da] República Federativa do Brasil, Brasília, DF, 21 set. 1988.

BLUNDELL, R. W.; BOND, S. R. Initial conditions and moment restrictions in dynamic panel data models. Journal of Econometrics, v. 87, n. 1, p. 115-143, 1998.

BOYD, J.; DE NICOLÓ, G.; JALAL, A. Bank risk-taking and competition revisited: new theory and new evidence. IMF Working Paper 06/297, International Monetary Fund, Washington, DC, 2006. 
CAMARGO, P. O. A evolução recente do setor bancário no Brasil. 1. ed. São Paulo: Editora UNESP, 2009.

CARLSON, M. Are branch banks survivors? Evidence from depression era. Economic Inquiry, v. 42, n. 1, p. 111-126, 2004.

CHIARAMONTE, L.; CROCI, E.; POLI, F. Should we trust Z-score? Evidence from the European banking industry. Global Finance Journal, v. 28, p. 111-131, 2015.

DEYOUNG, R.; ROLAND, K. P. Product mix and earnings volatility at commercial banks: evidence from a degree of total leverage model. Journal of Financial Intermediation, v. 10, n. 1, p. 54-84, 2001.

ELSAS, R.; HACKETHAL, A.; HOLZHÄUZER, M. The anatomy of bank diversification. Journal of Banking \& Finance, v. 34, n. 6, p. 1274-1287, 2010.

HAAN, J.; VLAHU, R. Corporate governance of banks: A survey. Journal of Economic Surveys, v. 30, n. 2, p. 228-277, 2016.

HAGGARD, K. S.; HOWE, J. S. Are banks opaque? International Review of Accounting, Banking and Finance, v. 4, n. 1, p. 51-72, 2012.

JONES, J. S.; LEE, W. Y.; YEAGER, T. J. Opaque banks, price discovery, and financial instability. Journal of Financial Intermediation, v. 21, n. 3, p. 383-408, 2012.

LAEVEN, L.; LEVINE, R. Bank governance, regulation and risk taking. Journal of Financial Economics, v. 93, n. 2, p. 259-275, 2009.

LEHAR, A. Measuring systematic risk: a risk management approach. Journal of Banking \& Finance, v. 29, n. 10, p. 2577-2603, 2005.

LEPETIT, L.; NYS, E.; ROUS, P.; TARAZI, A. Bank income structure and risk: an empirical analysis of European banks. Journal of Banking \& Finance, v. 32, n. 8, p. 1452-1467, 2008.

; STROBEL, F. Bank insolvency risk and time-varying Z-score measures. Journal of International Financial Markets, Institutions \& Money, v. 25, n. 1, p. 73-87, 2013.

MERCIECA, S.; SCHAECK, K.; WOLFE, S. Small European banks: benefits from diversification? Journal of Banking \& Finance, v. 31, n. 7, p. 1975-1998, 2007.

MONTGOMERY, C. A. Corporate diversification. Journal of Economic Perspectives, v. 8, n. 3, p. 163-178, 1994.

MORGAN, D. P. Rating banks: Risk and uncertainty in an opaque industry. The American Economic Review, v. 92, n. 4, p. 874-888, 2002.

PAULO, E.; MEDEIROS, O. R.; DANTAS, J. A. Relação entre concentração e rentabilidade no setor bancário brasileiro. Revista Contabilidade \& Finanças, v. 22, n. 55, p. 5-28, 2011.

PENAS, M. F.; UNAL, H. Gains in bank mergers: evidence from the bond markets. Journal of Financial Economics, v. 74, n. 1, p. 149-179, 2004.

SANFINS, M., MONTE-MOR, D. RiD: Uma Nova Abordagem para o Cálculo do Risco de Insolvencia. Revista Brasileira de Finanças, v. 12, n. 2, p. 1-27, 2014.

SANYA, S.; WOLFE, S. Can banks in emerging economies benefit from revenue diversification? Journal of Financial Services Research, v. 40, n. 1-2, p. 79-101, 2011.

STIROH, K. J. Diversification in banking: is noninterest income the answer? Journal of Money, Credit and Banking, v. 36, n. 5, p. 853-882, 2004a.

Do community banks benefit from diversification? Journal of Financial Services Research, v. 25, n. $2-3$, p. $135-160,2004 b$.

New evidence on the determinants of bank risk. Journal of Financial Services Research, v. 30, n. 3, p. 237-263, 2006.

TRUJILLO-PONCE, A. What determines the profitability of banks? Evidence from Spain. Accounting and Finance, v. 53, n. 2, p. 561-586, 2013.

YEYATI, E. L.; MICCO, A. Concentration and foreign penetration in Latin America banking sectors: impact on competition and risk. Journal of Banking \& Finance, v. 31, n. 6, p. 1633-1647, 2007. 